\title{
Why the concept of schizophrenia is still alive and kicking
}

\author{
R. S. Kahn ${ }^{1,2 *}$ \\ ${ }^{1}$ Department of Psychiatry, Icahn School of Medicine at Mount Sinai, New York, NY, USA \\ ${ }^{2}$ Department of Psychiatry, Brain Center Rudolf Magnus, Utrecht, The Netherlands
}

Received 14 February 2017; Revised 28 June 2017; Accepted 29 June 2017; First published online 26 October 2017

Key words: Bipolar illness, diagnosis, schizophrenia.

In their paper 'The slow death of the concept of schizophrenia' Guloksuz and Van Os have elegantly written about the (ir)relevance of the schizophrenia diagnosis. They make the point that this diagnosis not only carries the negative connotation of poor outcome and (hence) stigma; they also argue that schizophrenia is non-specific, showing overlap with (amongst others) bipolar disorder. How much more useful and more humane would it be, in their eyes, to focus on the more prevalent phenotype: psychosis.

There is much value, both clinically and scientifically in their proposition to study psychosis in the population, and the various component parts of this phenotype, such as hallucinations and delusions. Similarly, their statement rings true that the (ultra) high risk concept of schizophrenia, focusing on psychosis as it does, has been proven inadequate in predicting transition to schizophrenia - especially because of this limited focus and even more narrow outcome (Cannon et al. 2016). Indeed, in adolescence the route to psychiatric illness is broad and rather ill-defined (Mesman et al. 2013) providing an interesting field of research into the pathways to psychiatric illness, a field that has indeed been hampered by the aforementioned constricted definition of high-risk.

However, their main thesis that the diagnosis of schizophrenia is neither valid nor useful is not as well supported by the data as they would like to suggest. First, bipolar disorder and schizophrenia show many more differences than the response to lithium (which they cannot and do not dispute; that lithium reduces the affective symptoms of schizophrenia is of course not the same as being effective as a monotreatment for schizophrenia, which it is not). High IQ is a risk factor for bipolar illness; in schizophrenia the risk is increased by low IQ (Maccabe et al. 2010;

\footnotetext{
* Address for correspondence: R. S. Kahn, M.D., Ph.D., Department of Psychiatry, Brain Center Rudolf Magnus, Utrecht, The Netherlands. (Email: R.Kahn@umcutrecht.nl)
}

Vreeker et al. 2016). Intracranial volume is reduced in schizophrenia (Haijma et al. 2013), in bipolar illness it is increased (Hulshoff Pol et al. 2012), suggesting differences in brain development between both disorders. And finally, the often-quoted genetic overlap between both disorders is smaller than the difference in genetic risk profiles, both for common and rare variants (Neale \& Sklar, 2015). In short, schizophrenia does differentiate from bipolar disorder, clinically as well as biologically.

However, the Achilles heel in their argument is the basis on which it is founded: that schizophrenia should be understood as a form, severe or not, of psychosis. Indeed, they argue that Kraepelin's dichotomy is a false one, since psychosis is part of both schizophrenia and bipolar illness; that both disorders are cyclical and that schizophrenia can have a good outcome. All are true and uncontested. However, as they could have read, Kraepelin did not define schizophrenia on the basis of psychosis. He delineated the illness on the basis of the cognitive decline preceding the onset of psychosis - by many years. Indeed, in his original description of the illness, his account of the cognitive (and social) decline literally precedes the discussion of psychotic symptoms by many pages, indicating the relative priority - both in chronology and in relevance - he attributed to cognition rather than psychosis. Indeed, whether based on populationwide samples (Kendler et al. 2016), birth cohorts (Meier et al. 2014) or longitudinal high-risk studies (Seidman et al. 2016), all studies show that it is the cognitive decline preceding psychosis, much more than psychotic symptoms per se, that predict the onset of schizophrenia. That is why, on the basis of these and other data, we have argued that schizophrenia should be conceptualized as a cognitive, rather than a psychotic disorder (Kahn \& Keefe, 2013).

In summary, Goluksuz and van Os come up short in their argument that the concept of schizophrenia is slowly dying. Yes, when viewed through the narrow prism of psychosis, schizophrenia is not unique and 
not a useful concept. Indeed, if psychosis it is we want to study, we should follow the lead Guloksuz and van Os provide in their paper: study the phenotype in the population in all their aspects of severity. However, if the goal is understanding, the illness that starts with cognitive and social decline - with psychosis a late (albeit prominent) symptom - we cannot do without the concept first delineated by Kraepelin. In fact, elucidating the causes and consequences of cognitive decline in psychiatric illness may not only be necessary to understand schizophrenia; it will help to differentiate this syndrome from the others it is confused with (Keefe \& Kahn, 2017). A need amply demonstrated by the paper of Guloksuz and van Os. The questions they raise are relevant, their proposed solutions are not.

\section{References}

Cannon TD, Yu C, Addington J, Bearden CE, Cadenhead KS, Cornblatt BA, Heinssen R, Jeffries CD, Mathalon DH, McGlashan TH, Perkins DO, Seidman LJ, Tsuang MT, Walker EF, Woods SW, Kattan MW (2016). An individualized risk calculator for research in prodromal psychosis. American Journal of Psychiatry 173, 980-988.

Haijma SV, Van Haren N, Cahn W, Koolschijn PC, Hulshoff Pol HE, Kahn RS (2013). Brain volumes in schizophrenia: a meta-analysis in over 18000 subjects. Schizophrenia Bulletin 39, 1129-1138.

Hulshoff Pol HE, van Baal GC, Schnack HG, Brans RG, van der Schot AC, Brouwer RM, van Haren NE, Lepage C, Collins DL, Evans AC, Boomsma DI, Nolen W, Kahn RS (2012). Overlapping and segregating structural brain abnormalities in twins with schizophrenia or bipolar disorder. Archives of General Psychiatry 69, 349-359.

Kahn RS, Keefe RSE (2013). Schizophrenia is a cognitive illness. JAMA Psychiatry 70, 1107-1112.

Keefe RSE, Kahn RS (2017). Cognitive decline and disrupted cognitive trajectory in schizophrenia. JAMA Psychiatry 74, 535.
Kendler KS, Ohlsson H, Mezuk B, Sundquist JO, Sundquist K (2016). Observed cognitive performance and deviation from familial cognitive aptitude at age 16 years and ages 18 to 20 years and risk for schizophrenia and bipolar illness in a Swedish national sample. JAMA Psychiatry 73, 465-471.

Maccabe JH, Lambe MP, Cnattingius S, Sham PC, David AS, Reichenberg A, Murray RM, Hultman CM (2010). Excellent school performance at age 16 and risk of adult bipolar disorder: national cohort study. British Journal of Psychiatry 196, 109-115.

Meier MH, Caspi A, Reichenberg A, Keefe RS, Fisher HL, Harrington H, Houts R, Poulton R, Moffitt TE (2014). Neuropsychological decline in schizophrenia from the premorbid to the postonset period: evidence from a population-representative longitudinal study. American Journal of Psychiatry 171, 91-101.

Mesman E, Nolen WA, Reichart CG, Wals M, Hillegers MH (2013). The Dutch bipolar offspring study: 12-year follow-up. American Journal of Psychiatry 170, 542-549.

Neale BM, Sklar P (2015). Genetic analysis of schizophrenia and bipolar disorder reveals polygenicity but also suggests new directions for molecular interrogation. Current Opinion in Neurobiology 30, 131-138.

Seidman LJ, Shapiro DI, Stone WS, Woodberry KA, Ronzio A, Cornblatt BA, Addington J, Bearden CE, Cadenhead KS, Cannon TD, Mathalon DH, McGlashan TH, Perkins DO, Tsuang MT, Walker EF, Woods SW (2016).

Association of neurocognition with transition to psychosis: baseline functioning in the second phase of the north American prodrome longitudinal study. JAMA Psychiatry 73, 1239-1248.

Vreeker A, Boks MP, Abramovic L, Verkooijen S, van Bergen AH, Hillegers MH, Spijker AT, Hoencamp E, Regeer EJ, Riemersma-Van der Lek RF, Stevens AW, Schulte PF, Vonk R, Hoekstra R, van Beveren NJ, Kupka RW, Brouwer RM, Bearden CE, MacCabe JH, Ophoff RA, GROUP Investigators (2016). High educational performance is a distinctive feature of bipolar disorder: a study on cognition in bipolar disorder, schizophrenia patients, relatives and controls. Psychological Medicine 46, 807-818. 